\title{
Estudios y Tendencias \\ DE LA Política Y LAS \\ RELACIONES \\ INTERNACIONALES
}

Fabio Sánchez y Nicolás Liendo Editores 


\section{ESTUDIOS Y TENDENCIAS DE LA POLÍTICA Y LAS RELACIONES INTERNACIONALES}

Fabio Sánchez y Nicolás Liendo

\section{Editores}

Escuela de Política y Relaciones Internacionales

Universidad Sergio Arboleda

Bogotá, Colombia

2018

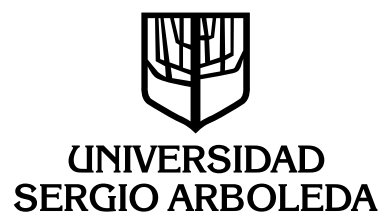


Estudios y tendencias de la política y las relaciones internacionales / Fabio Sánchez y Nicolás Liendo, editores ; Andrés Ortega ... [et al.] - Bogotá: Universidad Sergio Arboleda. Escuela de Política y Relaciones Internacionales, 2018.

$318 \mathrm{p}$.

ISBN: 978-958-55 I I-53-8 (rústica)

CIENCIAS POLÍTICAS 2. RELACIONES INTERNACIONALES 3. CONFLICTO ARMADO - COLOMBIA 4. SEGURIDAD INTERNACIONAL 5. PARTIDOS POLÍTICOS - COLOMBIA I. Sánchez, Fabio, ed. II. Liendo, Nicolás, ed. III. Ortega, Andrés IV. Ortega, Bibiana V. Niño, CésarVI. Martínez, Diego VII. Quintero, Germán VIII. Jaramillo, Felipe IX. Sergio Ángel X. Losada, Rodrigo

320 ed. 22

\section{Estudios y Tendencias de la Política y las Relaciones Internacionales}

ISBN: 978-958-5511-53-8 (rüstica)

ISBN: 978-958-5511-54-5 (.pdf)

DOI: $10.22518 /$ book/9789585511545

\section{(C) Escuela de Política y Relaciones Internacionales}

Universidad Sergio Arboleda

Andrés Ortega, Bibiana Ortega, César Niño, Diego Martínez, Fabio Sánchez, Germán Quintero, Felipe Jaramillo, Nicolás Liendo, Sergio Ángel, Rodrigo Losada.

Este libro tuvo un proceso de arbitraje doble ciego.

Primera Edición, diciembre de 2018

Fondo de Publicaciones de la Universidad Sergio Arboleda.

El contenido del libro no representa la opinión de la Universidad Sergio Arboleda y es responsabilidad del autor.

\section{(c) (1) (3)}

Atribución-NoComercial-SinDerivar 4.0 Internacional (CC BY-NC-ND 4.0).

\section{Edición:}

Diana Patricia Niño Muñoz

Deisy Janeth Osorio Gómez

Dirección de Publicaciones Científicas

Director del Fondo de Publicaciones:

Jaime Arturo Barahona Caicedo

jaime.barahona@usa.edu.co

Corrección de estilo:

Sonia Girón

Revisión de normas técnicas:

Logomante, industrias de la creatividad y el lenguaje

Diego Ávila Jacobo

Diagramación:

Myriam Enciso Fonseca

Fotografía de portada:

Fabio Sánchez Cabarcas

Calle 74 No. 14-14.

Teléfono: (571) 3257500 ext. 2131/2260.

Bogotá, D.C.

www.usergioarboleda.edu.co

Impresión: DGP Impresores Bogotá, D.C. 


\section{Contenido}

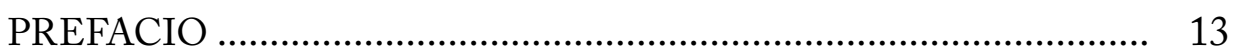

Fabio Sánchez y Nicolás Liendo

INTRODUCCIÓN A LA CIENCIA POLÍTICA .............................. 17

Diego Martinez

De la Filosofía Política a la Ciencia Política .................................. 18

El término política. ................................................................. 18

La Filosofía Politica. ............................................................. 20

La ciencia politica. ................................................................... 22

El paso de la Filosofía Política a la Ciencia Política........................ 24

El positivismo y sus críticas. ...................................................... 26

Conceptos claves en la Ciencia Política ......................................... 27

Polity, Policy y Politics. ........................................................... 27

Sistema politico. ...................................................................... 29

El poder. ........................................................................ $\quad 30$

Legitimidad. .................................................................... 31

Sobre legalidad y legitimidad. .............................................. 33

La Institucionalización de la Ciencia Política ............................... 34

La escuela de Chicago (1920-1940). .......................................... 35

El conductismo. .................................................................... 35

El método matemático y los modelos económicos de la elección

racional. ........................................................................... 36

La Ciencia Política en América Latina ......................................... 38

La institucionalización de la Ciencia Política. ............................ 38

La historia de la Ciencia Politica en Colombia............................ 39 
La historia de la Ciencia Politica en la Universidad Sergio Arboleda. ............................................................................ 40

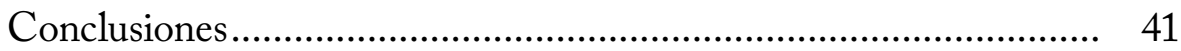

Referencias......................................................................... 42

LOS PARTIDOS POLÍTICOS ¿PARA DÓNDE VAN?..................... 53 Rodrigo Losada

¿Qué se Entiende por Partido Político? .......................................... 54

Evolución del Fenómeno Partidos Politicos.................................... 57

Los Tiempos cambian e Igualmente los Partidos........................... 63

Ideologías Políticas en Colombia................................................. 64

Los Partidos y la Representación Política...................................... 66

El Origen de los Partidos Colombianos ....................................... 68

Características Selectas de los Actuales Partidos Colombianos....... 72

Conclusiones ......................................................................... 76

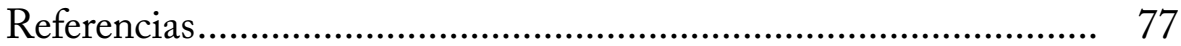

TEORÍA POLÍTICA ............................................................... 81

Germán Quintero

Generalidades de la Teoría Política .............................................. 82

La Teoría Politica entendida como toda reflexión sobre lo politico. ... 84

La Teoría Politica entendida como Filosofía Politica. ................... 84

La Teoría Politica entendida como una subdisciplina

de la Ciencia Politica. .............................................................. 86

La Teoría Politica entendida como ideología. .............................. 87

Historia de la Teoría Política....................................................... 88

Inicios de la Teoría Política. ....................................................... 88

Teoría Política en la Edad Media. ............................................... 91

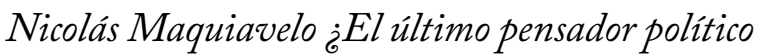

de la teoría política clásica? .......................................................... 92 
Excursus: Maquiavelo vs Kant. ................................................ 93

Teorías Contractualistas ............................................................ 94

Elementos del Contrato Social. ................................................... 95

El padre de las teorias modernas contractuales: Thomas Hobbes. ..... 96

El Leviatán. .................................................................... 97

Teorías Políticas Contemporáneas .............................................. 99

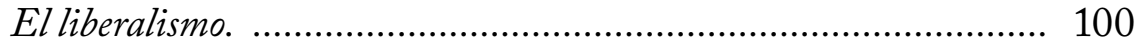

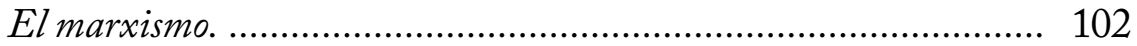

John Rawls: teoría de la justicia y sus críticos. ............................. 102

Comunitarismo. ................................................................ 104

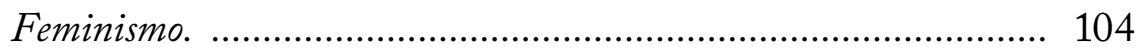

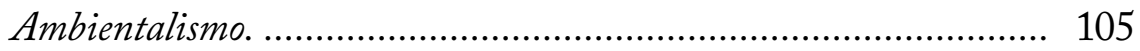

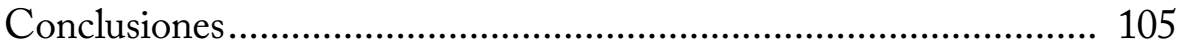

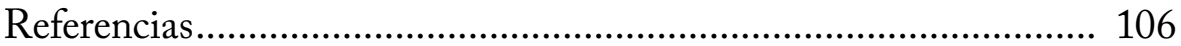

POLÍTICA COMPARADA …....................................................... 115

Nicolás Liendo y Bibiana Ortega

¿Qué, cómo, por qué, para qué?................................................. 115

El Estado ¡cómo y cuándo surge? ................................................ 119

Regímenes Políticos ................................................................ 122

¿Cómo medir la democracia? ....................................................... 124

Formas de Gobierno ................................................................. 130

Parlamentarismo. ................................................................. 130

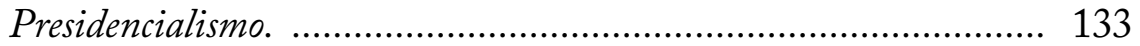

Semipresidencialismo. ......................................................... 135

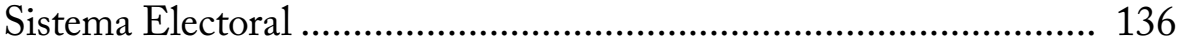

Fórmula Electoral. .............................................................. 138

Circunscripciones Electorales ................................................... 140

Posibilidad de reelección y duración del mandato. .......................... 141

Conclusiones........................................................................... 143

Referencias....................................................................... 143 
CONFLICTO ARMADO COLOMBIANO:

REFLEXIONES Y CUESTIONES ESTRUCTURALES

César Niño y Andrés Ortega

¿Violencia y Conflicto son lo mismo?

¿Cuáles fueron las razones del inicio del conflicto armado

y de la violencia?

¿Qué pasaba en el resto del continente? 156

¿Y el narcotráfico?

Efectos Políticos-Electorales de la Violencia 161

Fin del Conflicto... Pero con las FARC 163

Los Retos de la Implementación de la Paz 166

A Manera de Cierre 169

Referencias.

EL PROCESO DE INVESTIGACIÓN

EN CIENCIA POLÍTICA

Sergio Ángel

La Investigación en Ciencia Política .............................................. 183

Enfoques y Métodos en Ciencia Política ....................................... 188

Nuevas Tecnologías en el Proceso de Investigación........................ 192

Gestores bibliográficos. ............................................................. 195

Gestión del proyecto de investigación. ......................................... 197

Mapas de conocimiento. ......................................................... 199

Sistemas de gestión de información. ............................................ 201

Portales académicos. ............................................................. 202

La Política de la Ciencia y la Circulación del Saber......................... 203

Producción Científica en Ciencias Sociales y en Ciencias

Naturales ................................................................................. 210

Referencias....................................................................... 216 


\section{INTRODUCCIÓN A LAS RELACIONES}

INTERNACIONALES ............................................................... 221

Felipe Jaramillo Ruiz

Las Historias Sobre el Origen de las RR. II................................ 222

Las Tradiciones de Pensamiento de las RR.II. ............................. 224

El Objeto de Estudio de las RR. II. ............................................ 226

La Ontología, Epistemología y Método de las RR. II..................... 228

La Objetividad en las RR. II.................................................... 230

La Escuela Positivista de las RR.II. ............................................ 232

El debate agente-estructura ..................................................... 235

El Problema de los Niveles de Análisis ........................................ 237

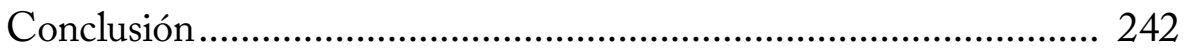

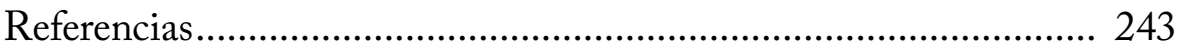

GLOBALIZACIÓN Y AGENDA DE ESTUDIO ............................ 251

Fabio Sánchez

Orígenes de los Estudios Sobre Globalización............................... 255

Mirada Disciplinar ................................................................ 257

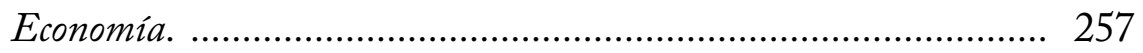

Sociología. .................................................................... 258

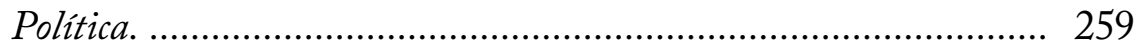

Relaciones Internacionales. .................................................... 260

Perspectivas de Análisis ............................................................ 261

Hiperglobalistas. ................................................................ 261

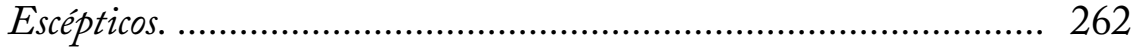

Transformacionalistas. ........................................................ 263

Agenda de Estudio ....................................................................... 264

Tecnología e industrias culturales (Tecnocultura). ......................... 265

Medio ambiente, migraciones y desarrollo. .................................. 266

Intervención humanitaria, conflictos y genocidio. ......................... 269 
Antiglobalización o ¿Frenar lo Imposible? ..................................... 270

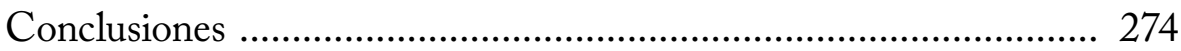

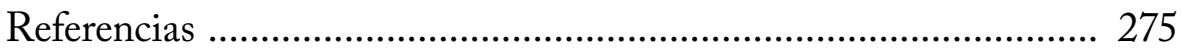

SEGURIDAD EN LAS RELACIONES

INTERNACIONALES CONTEMPORÁNEAS:

UNA MIRADA PARA ESTUDIANTES DE LA DISCIPLINA ....... 283

César Niño

Las Nociones de la Seguridad ....................................................... 284

El Rol del Estado y Algunos Aportes Sobre la Seguridad............... 288

Una Visión Ampliada: ¿Qué más entra en la agenda

de seguridad? .............................................................................. 290

Las Amenazas y los Problemas de Seguridad............................... 294

¿Cómo ingresa un tema a la agenda de seguridad? .......................... 296

El Terrorismo como Asunto de Seguridad en

las Relaciones Internacionales ...................................................... 297

¿Quién es denominado terrorista? ................................................ 301

Breve Explicación Sobre la Seguridad y la Defensa

en América Latina ........................................................................ 301

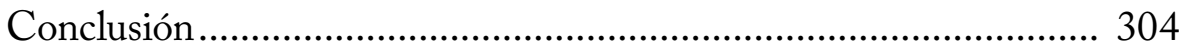

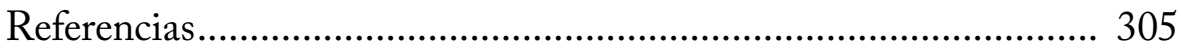

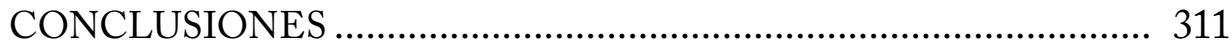

Fabio Sánchez y Nicolás Liendo

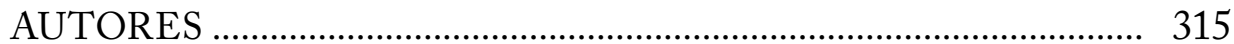




\title{
Conflicto Armado Colombiano: Reflexiones y Cuestiones Estructurales
}

César Niño"

Andrés Ortega*

\begin{abstract}
Abordar la historia del conflicto armado de Colombia en unas cuantas páginas, implica sintetizar cuestiones que han sido parte tanto de su historia como de su realidad contemporánea; así mismo, advertir que las causas del conflicto tienen tan solo una variable o una única fuente. Ambas implicaciones son per se un error académico, social e histórico (Kalyvas, 2009). Por ello, es menester entablar algunas reflexiones y cuestiones estructurales que diluciden ciertas interpretaciones sobre los orígenes, el desenvolvimiento, la vigencia y la mutación de la violencia en el país.
\end{abstract}

Más allá de hacer una simple cronología y recorrido por las décadas que protagonizaron el conflicto y la violencia, este capítulo se desarrollará de la siguiente manera: la primera parte; diferencia entre violencia y conflicto como categorías analíticas centrales del texto; la segunda parte, resume las causas históricas del conflicto; en tercer lugar, revisa a los actores del conflicto con particular énfasis en el narcotráfico; en cuarto lugar, aborda una perspectiva novedosa en los estudios del conflicto con gran importancia en la agenda académica del país, a saber: los efectos político-electorales. En quinto lugar,

* Profesor Asociado, Grupo de Análisis Político (GAP), Escuela de Política y Relaciones Internacionales, Universidad Sergio Arboleda. Correo electrónico: cesar.nino@usa.edu.co (1.) 0000-0002-1417-6643

** Profesor Asistente, Escuela de Política y Relaciones Internacionales, Universidad Sergio Arboleda. Correo electrónico: andresf.ortega@usa.edu.co 
explica la fase actual de implementación del proceso de paz y el fin del conflicto con las FARC. Finalmente, se presentan algunas conclusiones.

\section{¿Violencia y Conflicto son lo mismo?}

En la discusión sobre las causas del conflicto armado en Colombia, vale la pena aclarar que el fenómeno de la violencia es distinto del conflicto armado. La violencia es un término ambiguo y de difícil consenso entre los académicos y estudiosos de las ciencias sociales. De hecho, la imprecisión del concepto logra abrir brechas tanto epistemológicas como jurídicas con implicaciones peligrosas, dado que si hay vacíos en su definición y alcance, no se comprendería, entonces, quién tendría la categoría de víctima. No obstante, para efectos de este capítulo, es necesario arrojar algunas definiciones que pueden acercarse a la realidad.

Para empezar, Oquist (1978) realiza una taxonomía interesante sobre la violencia: la violencia racional y la violencia irracional. La primera, hace hincapié en que este tipo de violencia es "el medio utilizado para alcanzar un fin potencialmente realizable” (Oquist, 1978, p. 37), como la violencia en el contexto colombiano. Mientras que la violencia irracional, según el autor, es la agresión física o la amenaza de esta que no persigue una meta, pues tiene a la propia violencia como meta final (Oquist, 1978). Y en un terreno mucho más amplio, como el de la política internacional. Galtung (1990) ha definido la violencia como la degradación de los conflictos, de manera que, también, hace una clasificación sobre tres tipologías de violencia:

Violencia directa. Es manifestada a través de la conducta y se materializa con comportamientos que agreden la parte física o mental del otro.

Violencia estructural. Es la estructura de la violencia, es decir, de esta emanan las complejidades que tienen como respuesta las hostilidades. 
Violencia cultural. Aquellos aspectos de la cultura, la esfera simbólica como la religión y la ideología, en el lenguaje y el arte, que pueden ser usados para justificar la violencia directa o la violencia estructural (Galtung, 1990).

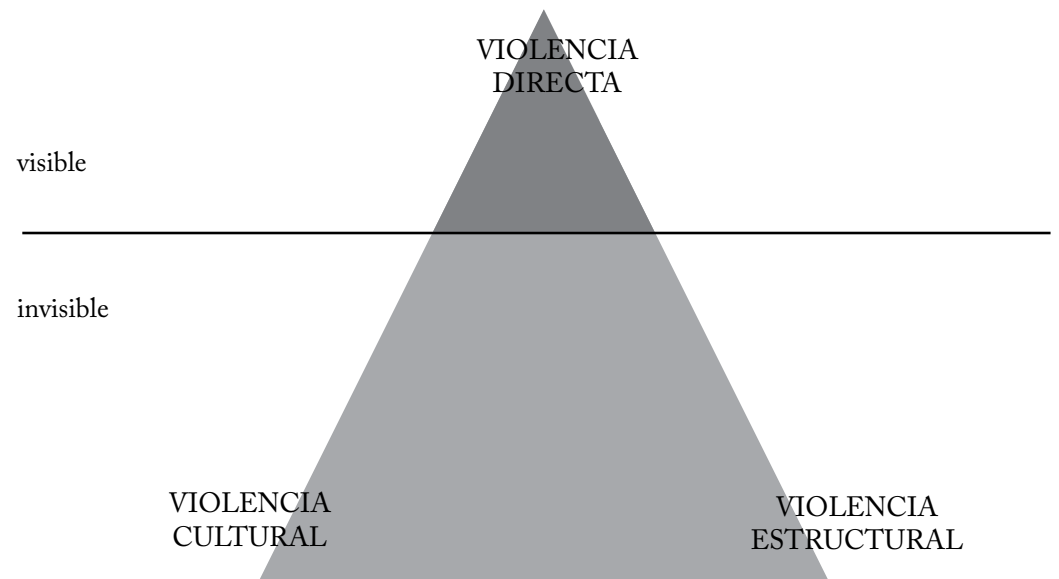

Figura 5.1. Triángulo de la violencia. Basado en "La violencia: cultural, estructural y directa” por J. Galtung, 1990.

No obstante, para Galtung (2003), el conflicto es obvio en la sociedad, pero no la violencia y, por tanto, el conflicto no necesariamente tiene que finalizar en violencia física y verbal. El fracaso en la transformación del conflicto es lo que conduce a la violencia (Hueso, 2000).

\section{¿Cuáles fueron las razones del inicio del conflicto armado y de la violencia?}

Colombia tiene aproximadamente 49 millones de habitantes según la información cruzada entre el Departamento de Estadística Nacional y el Banco Mundial (Banco Mundial, 2018 y Departamento Nacional de Estadística, 2018), es decir, es factible advertir que puede haber alrededor de 49 millones de versiones de la historia del conflicto armado en el país (Niño, 2017). Según lo anterior, la multicausalidad de los fenómenos que dieron lugar a las 
violencias y conflictos, es un factor relevante para tener en cuenta al momento de analizar el conflicto colombiano. En todo caso, este es un factor que ha sido resaltado por distintos autores que han participado en la realización de diagnósticos respecto a las causas de nuestro conflicto (Comisión de Estudios sobre la Violencia, 1987).

Nótese, por ejemplo, que en el último intento explicativo de las causas que dan origen al conflicto y su persistencia, La Comisión Histórica para el Conflicto y sus Víctimas (CHCV) en el marco de la negociación con las FARC, cada uno de los participantes propone una narrativa distinta sobre el desarrollo del conflicto. A pesar de eso, Pizarro (2015) reconoce algunos ejes interpretativos comunes, a saber: "la cuestión agraria, la debilidad institucional, la honda desigualdad de los ingresos, la tendencia al uso simultáneo de las armas y las urnas o la presencia precaria o, en algunas ocasiones, traumática del Estado en muchas regiones del territorio nacional" (p. 6).

No obstante, conocemos un poco de los efectos humanitarios que este ha dejado. Cabría reconocer que respecto al tema de víctimas es importante la atención a las mismas, pues el aspecto fundamental de toda medida que se encamine hacia las víctimas debe ser, ante todo, evitar la impunidad y garantizar el restablecimiento de los derechos. Así pues, en el marco de lo que se conoce como el Derecho Internacional, existe una serie de principios contra la impunidad que promulgó Naciones Unidas (y que se conoce como los Principios Joinet), documento que señala cuáles son las obligaciones fundamentales que tiene todo Estado respecto a los derechos fundamentales a los que toda víctima tiene derecho en el contexto de las violaciones a los Derechos Humanos y el Derecho Internacional Humanitario. Entre ellos, sobresalen: Derecho a la verdad, a la justicia y a la reparación. A ellos se suman las garantías de no repetición. 
Con respecto a lo anterior, cabe decir que en el país hay registradas 8679002 víctimas de conflicto armado, de acuerdo con la Unidad de Víctimas y Restitución de Tierras ${ }^{1}$.

Los conflictos armados internos, en general, han sido materia de estudios predominantemente sociológicos y politológicos (Arjona, Kasfir y Mampilly, 2015; Gutiérrez-Sanín y Wood, 2017; Kalyvas, 2006; Wimmer, 2013; Wood, 2003). De esta forma, ${ }^{2}$ se han estudiado los orígenes de conflictos referentes a la exclusión política e ideológica, al descontento de la población con el Estado (Gurr, 1970), a la influencia marxista, a la presencia de recursos económicos (Collier, 1998) y a la tensión reinante en la Guerra Fría entre Estados Unidos y la Unión Soviética (Guáqueta, 2002). Si bien el conflicto colombiano, como actualmente se conoce, registra sus inicios a mediados de los años sesenta, lo cierto es que hunde sus raíces en una suerte de acontecimientos, especialmente convulsos, de la década de los cuarenta (Campos, Fals-Borda y Umaña, 2005; Gutiérrez-Sanín, 2014a; Meertens y Sánchez, 1983; Ortiz, 1985).

Durante décadas, dentro de la academia colombiana se han venido tejiendo distintas hipótesis sobre la génesis de la violencia en el país (Grasa, 2017). Por un lado, están quienes, mostrando las razones basadas en los problemas de tenencia de la tierra en tensión con la ausencia del Estado y las consecuencias que de este se derivan, y, por otro, las lógicas de la polemología (sociología de la guerra) y de la irenología (estudios de la paz) en clave de conflicto social en el marco de la dimensión de la seguridad nacional. En ese orden de ideas, la literatura ofrece enfoques alternativos para explicar los fenómenos de conflicto interno. El debate más importante se presenta entre los que sostienen que la violencia es el resultado de factores económicos y aquellos que afirman que los conflictos internos se originan debido a variables tales como la debilidad de las instituciones, los conflictos por la tierra

1 Para mayor información consultar: unidad para la atención y reparación integral de víctimas. Disponible en https://www.unidadvictimas.gov.co/

2 Dos referencias para abordar el tema de guerras civiles se encuentran en los textos de Kalyvas (2009) y (Newman y Jr., 2014) 
(LeGrand, 2016), el tipo de régimen (Gutiérrez-Sanín, 2014a), la presencia estatal (González, 2014) y la inclusión -o exclusión- política (Yaffe, 2011).

De tal manera, hacer arqueología para determinar las causas del conflicto y la violencia, conlleva realizar una profunda reflexión. Partiendo del hecho de que la violencia y el conflicto vienen espontáneamente desde la segunda mitad del siglo XX (Gutiérrez, 2014b), los medios de comunicación y la opinión pública en general han sido responsables de las interpretaciones erróneas. Así entonces, vale la pena mencionar que el fenómeno de la violencia y la naturaleza del conflicto no son recientes, de hecho, durante buena parte del siglo XIX, en Colombia hubo más de una veintena de enfrentamientos violentos entre los dos partidos políticos tradicionales del momento -el Partido Conservador y el Partido Liberal-(Ríos, 2017). Dichos enfrentamientos y la exacerbación de la violencia partidista fueron medios para caldear la historia decimonónica del país que desembocó en la guerra de los Mil Días y con ella la pérdida de Panamá en 1903. Este último acontecimiento protagonizó el primer conflicto armado del siglo XX en el mundo.

La historia del conflicto armado colombiano no es solo una historia de grupos alzados en armas, opuestos y enfrentados, sino que es la historia de la construcción de la nación, de un modelo económico, de una sociedad civil (Rodríguez, 2016) y de unas débiles instituciones estatales que cimentaron rivalidades y lógicas entrópicas en el territorio colombiano. El debate sobre los orígenes o sobre la multiplicidad de causas nunca se cierra (Pécaut, 2014). La ausencia de los poderes institucionales llevó a sectores poblacionales a acogerse a la protección de actores extralegales; así, en palabras de Weber (1964), el Estado empezó a perder el monopolio legítimo de la fuerza (Zuleta, 2015). Un correlato de esto fue la creación de órdenes informales de autoridad, que pusieron en cuestión la presencia y legitimidad del Estado (Arjona, 2008; 2015; Aguilera, 2013).

Desde una mirada más amplia, la violencia presente en los conflictos armados afecta claramente el desarrollo de los Estados debido a la inestabilidad 
(además de las violaciones a los derechos de las poblaciones). Producto de esta inestabilidad, los Estados se tornan incapaces de imponer orden a la sociedad, lo que evidencia el debilitamiento de las instituciones. En otras palabras, los Estados pierden, por efectos del conflicto (degradación y generalización), los monopolios clásicos que las teorías del Estado le otorgan (Weber, 1964).

Al hacer una sencilla retrospectiva sobre las causas del conflicto, conviene observar la década de 1920 como una etapa en la cual "comienza a tomar cuerpo una fase nueva en el desenvolvimiento de la sociedad colombiana" (Fajardo, 2014, p. 4). Según este autor, se confrontan dos proyectos de sociedad: uno afianzado en la valoración de la propiedad de la tierra, y otro confrontado con la propuesta de construcción de una economía nacional que se apoya en desarrollos industriales y en una sólida clase media rural (Fajardo, 2014). No obstante, es viable señalar que el conflicto se debió, entre otros, a factores endógenos, aunque según Jorge Giraldo (2015) tres cuestiones exógenas incidieron, a saber: "la Guerra Fría, la guerra contra las drogas y la guerra contra el terrorismo" (p. 33). Así entonces, habiendo advertido hace algunas líneas sobre la intención del presente capítulo, en la historia entre la segunda y tercera década del siglo XX, hubo asuntos y procesos que condujeron al debilitamiento institucional y social, manifestados en la pausa del gobierno del presidente Eduardo Santos, el intento de golpe militar contra López Pumarejo y la expedición de la Ley 100 de 1944, la cual volcó a formas arcaicas el trabajo en las haciendas (Fajardo, 2014).

De manera paralela, mientras el campo colombiano estaba desolado y brillaba por la debilidad del Estado (Campos et al., 2005; Deas y Gaitán Daza, 1995), en las principales ciudades la disputa política y la tensión entre los dos partidos hegemónicos cobraban vidas y caldeaban el conflicto en otras dimensiones (Gutiérrez-Sanín, 2014b). Con base en lo anterior, es viable anotar que el país empezó a manifestar conflictos y violencias simultáneas por razones estructurales. Sin lugar a dudas, las causas son múltiples y se multiplican también a lo largo del tiempo. Lo que es causa en una fase se puede convertir en consecuencia en otra (Pécaut, 2014). 
Un punto de inflexión muy importante para tener en cuenta es el asesinato del líder del Partido Liberal el 9 de abril de 1948. Con tal acontecimiento se abre el periodo denominado LA Violencia, el cual trajo consigo la mayor movilización de campesinos, bandoleros, guerrilleros (Meertens y Sánchez, 1983) y autodefensas a lo largo y ancho del territorio nacional (Hobsbawm, 1974). En ese sentido, ese periodo se denominó así para hacer referencia al lapso entre 1946 y 1966, que protagoniza la violencia bipartidista liberal-conservadora y que antecedió a un nuevo tipo de violencia producto del surgimiento de las guerrillas. Esta se materializó por "la falta de voluntad política de las élites partidistas del momento” (Ríos, 2017, p. 27).

La Violencia, según Ríos (2017), enfrentó a campesinos liberales y conservadores, mientras los grandes propietarios de las tierras permanecían en las ciudades resguardados; lógica que contribuyó a una creciente asimetría entre el campo y la ciudad generando una ampliación de la brecha social y económica (Oquist, 1978).

\section{¿Qué pasaba en el resto del continente?}

Para la época, la región latinoamericana vivía sus propias convulsiones políticas. Por ejemplo, en Cuba la revolución de 1959, que derribó la dictadura de Fulgencio Batista fue el hito de América Latina en plena Guerra Fría porque un puñado de jóvenes estudiantes, en un país cercano a la costa de la Florida en Estados Unidos, pudo derrocar a un gobierno militar (Giraldo, 2015).

Esto fue la inspiración del surgimiento de grupos rebeldes en la mayor parte del mundo. Verbigracia, en marzo de 1959, un grupo panameño intentó formar la insurgencia armada, en junio fue en Nicaragua, en agosto en República Dominicana, en noviembre un grupo entró a Paraguay viniendo desde Brasil (Castro, 1998) y hacia 1969 ya había más de treinta grupos guerrilleros en diecinueve países de América Latina (Giraldo, 2015; Tulchin y Espach, 2001). 
El continente se encontraba en una constante ebullición ideológica, política y de seguridad. El contexto latinoamericano que atravesaba por enclaves dictatoriales, transiciones a la democracia y recrudecimiento de doctrinas de seguridad era un escenario heterogéneo con una pluralidad de actores que respondían a una particular homogeneidad regional: la debilidad y el vacío institucional. En efecto, lo que sucedía en Colombia no era un hecho atípico ni aislado en el continente, era más bien, un reflejo de una región asimétrica. Cuba tuvo un papel importante en los sentimientos revolucionarios y de insurgencia en América Latina, de hecho, La Habana desempeñó un papel clave como canal de suministro de armamento, entrenamiento y creación de doctrina (Giraldo, 2015) a una larga lista de movimientos armados latinoamericanos (Ortiz, 2000). Por ejemplo, el M-19 en Colombia tuvo un patrocinio importante en el abastecimiento de armas que logró preocupar a los operadores de seguridad en Bogotá, otro episodio de suministro de material bélico en Venezuela en los 60 y en Chile en los 80.

Colombia se adentró en una dinámica compleja. Mientras era evidente una resistencia liberal, los comunistas focalizaban su noción maoísta de guerra popular prolongada y el Estado implementaba una noción y doctrina de seguridad enclavada en la contrainsurgencia. Allí se abría paso para que en 1964 tanto en Tequendama como en Sumapaz (Cundinamarca) y en el sur del Tolima, nacieran las Fuerzas Armadas Revolucionarias de Colombia (Centro Nacional de Memoria Histórica, 2013; Medina Gallego, 2010; Pizarro, 2002; Pécaut, 2008). En este punto se muestra que la historia de la violencia y del conflicto no parte exclusivamente con la aparición de las FARC. El paramilitarismo tiene un cordón umbilical compartido con las guerrillas en Colombia, es decir, surge bajo la justificación de una fuerte ausencia del Estado (Gutiérrez-Sanín, 2014b; Ronderos, 2014), pero toma distancia de la naturaleza guerrillera en cuanto esta se forma como estrategia contrainsurgente ${ }^{3}$ y de gasto público. Ríos (2017) ilustra la importancia del poder local para los

3 Para consultar y hacer arqueología sobre la estrategia contrainsurgente del momento, véase el Decreto 3398 de 1965 que cambia a la ley 48 de 1968. En ella se faculta a la población civil para portar armas si está bajo escenarios de conflicto para luchar contra las guerrillas. Esto estuvo vigente hasta 1989. 
grupos armados, era un escenario complejo y con la interacción de actores que pretendían, además de la lucha contrainsurgente, generar dinámicas que les permitieran conservar sus intereses intactos frente a procesos que se estaban produciendo en el ámbito nacional, como los acuerdos de paz y la apertura del sistema político.

Adicionalmente, el paramilitarismo se construye como un fenómeno ligado a los escenarios locales y regionales del poder político. En este sentido, la hipótesis de Sánchez y Chacón (2007) en torno a la relación entre conflicto y descentralización política y de gasto público ilustra la importancia del poder local para los grupos armados.

Estos cambios institucionales tuvieron un efecto sustancial en la dinámica del conflicto armado interno, pues si el poder político y los recursos presupuestales se trasladaron a lo local, los grupos irregulares tendrían incentivos para tener mayor injerencia y control sobre el ámbito local, en particular dada la debilidad del Estado tanto en lo relativo al monopolio de la fuerza como a la administración de la justicia. Así, en la medida en que aumentaran su control sobre lo local -por la vía de la intimidación, de la depredación o de alianzas estratégicas con los dirigentes locales y regionales- accedían a una mayor porción de poder. (Sánchez y Chacón, 2017, pp. 350-351).

Para seguir analizando y reflexionando sobre la dinámica paramilitar en Colombia vale la pena preguntarse, ¿¿cuál es la diferencia entre el paramilitarismo y las autodefensas? Así, los paramilitares corresponden a "grupos armados organizados para realizar operaciones de limpieza política y consolidación militar, previas al dominio territorial de un área" y las autodefensas son "agrupaciones organizadas para defenderse de un agresor y mantener el control de un territorio, sin pretensiones de expansión" (Romero, 2003, p. 38). Sin embargo, el poder descriptivo de esa diferenciación fue perdiendo sentido en la medida en que los distintos grupos coincidieron a mediados de los años 90 -bien en la práctica o en la concepción sobre cómo superar el conflicto armado- con los organismos de seguridad de las fuerzas armadas 
(Romero, 2002). De este modo, los paramilitares se caracterizan por la naturaleza de formar condiciones para-institucionales.

\section{¿Y el narcotráfico?}

El fenómeno paramilitar, sumado a las debilidades institucionales, a los vacíos de poder y a los grupos guerrilleros, se convirtió en una dinámica conflictiva y violenta con un componente criminal por el narcotráfico. Entre las décadas de los 80 y 90 se protagonizaron las guerras entre carteles y la narcotización del conflicto armado colombiano. La historia política contemporánea de Colombia ha estado inmersa en una serie de marcos referentes a la actividad del narcotráfico. Se ha desenvuelto en un escenario donde aquel fenómeno permea de manera transversal la agenda política, económica y de seguridad del país (Niño, 2016). Así mismo, Camacho (2006) define que hay una estrategia de los narcotraficantes, retomada de P. Bourdieu, de enclasamiento, esto es, de copiar los patrones simbólico-culturales de la élite para "lograr aceptación social y así ascender en la escala social” (p. 398).

Los carteles de la droga en Colombia iniciaron su empresa trayendo la pasta de coca desde Ecuador y Perú y la traficaban con destino a Estados Unidos (Crandall, 2002; Gehring y Cuervo, 2013)

En materia de conflicto y crimen hay máximas que de manera directa son los caldos de cultivo para la generación estructural de los fenómenos. La ausencia y la debilidad del Estado como proveedor del orden interno y de servicios básicos, contribuyeron a la aparición, presencia y desenvolvimiento de la guerrilla y del narcotráfico en algunas áreas críticas del país (Mujica y Thoumi, 1996).

En este sentido, se puede afirmar que la simbiosis entre el fenómeno del narcotráfico y los grupos criminales tenía una explicación sistémica al ocupar un espacio vacío que había dejado la institucionalidad estatal (Niño, 2016). El narcotráfico había influido en la actividad política y en el sistema democrático 
bajo diferentes estrategias que entrecruzan, a lo largo de los últimos veinte años, los planos de lo legal / ilegal, así como el uso instrumental de la violencia (López y Sevillano, 2008). Los vínculos entre el narcotráfico y el conflicto armado en Colombia han generado un debate intenso tanto académico como político (Uprimny, Guzmán y Parra, 2012). Por un lado, según los autores recientemente citados, esta práctica ilícita habría alterado sustancialmente la naturaleza del conflicto armado colombiano, pasando a ser un despliegue de violencia por organizaciones ilegales que buscarían apropiarse de rentas ilícitas; por otro, sin negar el impacto de los dineros de la droga en el conflicto, esta sigue siendo una confrontación esencialmente política (Uprimny et al., 2012).

Por sus características delictivas y clandestinas, el narcotráfico no puede existir sin un aparato de represión (armas). De tal manera, la premisa inicial del narcotráfico es la creación de una poderosa fuerza armada que sirva para proteger a los "capos" de otros grupos narcotraficantes, de grupos guerrilleros (también, en algún momento mutaron al narcotráfico) y de las autoridades del Estado (Zuleta, 2015). Con base en dicha arquitectura criminal, a esas funciones de seguridad se les añade la intimidación y asesinato a jueces, magistrados, funcionarios del Estado, periodistas y a quienes entorpecieran sus objetivos. Entre 1994 y 2008, el narcotráfico ha causado cerca de 3800 homicidios al año, es decir, el 25\% de la tasa nacional (Garzón, 2013).

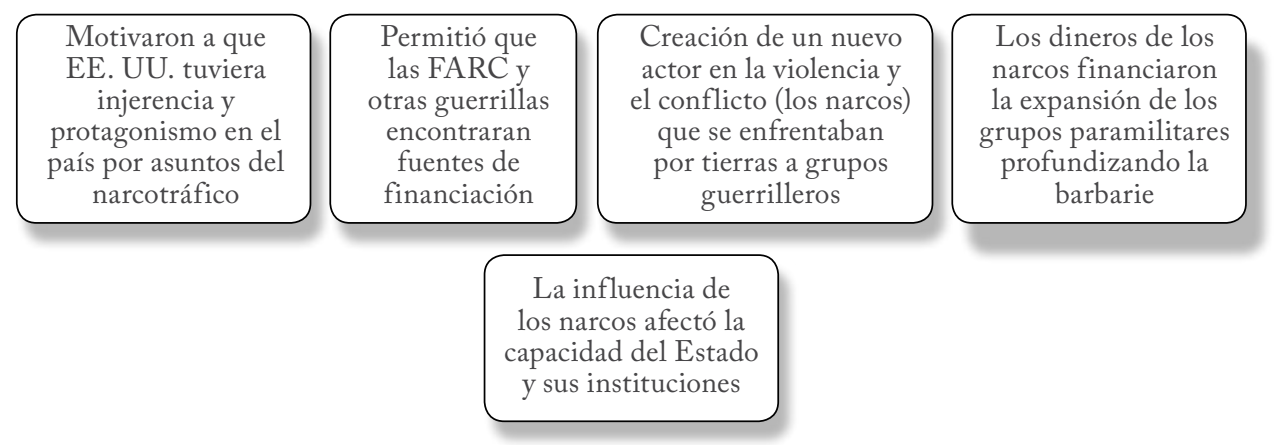

Figura 5.2. Transformación del conflicto por el narcotráfico. Elaboración propia con base en "Diálogos de paz y drogas: posibilidades en medio y más allá del prohibicionismo” por R. Uprimny, D. Guzmán y J. Parra, De Justicia, 28 de noviembre de 2012. 


\section{Efectos Políticos-Electorales de la Violencia}

Recientemente, se han empezado a discutir los efectos que la violencia y el conflicto pueden tener sobre las decisiones políticas que toman candidatos en el marco de su carrera política. El interrogante planteado implica empezar por reconocer el hecho de que el conflicto armado opera como un factor contextual en las decisiones de los candidatos (Gómez-Albarello y Rodríguez, 2007) como de los ciudadanos (García, 2010). La pregunta resulta pertinente en la medida en que no disponemos de estudios sobre la materia; de hecho, los estudios que existen en este campo de investigación suelen concentrarse en los efectos político-electorales del conflicto armado. Gutiérrez Sanín (2017), Hoyos (2008) y Acemoglu, Robinson y Santos (2009) revisan cuáles han sido los tipos de comportamiento en relación con los procesos electorales, enfatizando en la participación política de los ciudadanos.

De forma general, el argumento nos dice que la violencia incide en el funcionamiento de la democracia. Como respuesta a esta reflexión ha emergido un programa de investigación que busca enlazar estos dos campos de estudio: "por una parte, los estudios sobre las consolidaciones democráticas y, por otra parte, las causas, consecuencias y dinámicas de los conflictos armados" (Dunning, 2011, p. 327). Estos estudios se ven orientados por la siguiente pregunta de investigación: ¿Cómo el conflicto armado está relacionado con los ámbitos de la política electoral?

La respuesta a estas preguntas adopta dos formas principales. En una primera línea, se estudian ambos campos como substitutos estratégicos, donde los actores pueden usar la violencia para imponer sus intereses. En una segunda línea, el conflicto armado y las dinámicas político-electorales se analizan como complementos estratégicos, cuyos actores políticos pueden usar la violencia para alcanzar sus objetivos. Se argumenta, pues, que los incentivos electorales pueden cambiar la violencia.

Es necesario recalcar que existen unos estudios que se encargan de mostrar cómo la violencia política opera como un factor contextual que modifica 
las acciones, expectativas e incentivos de los individuos y su comportamiento político. Por ejemplo, Collier (1998) encuentran, para el caso nigeriano, que la violencia se usa de forma instrumental para mejorar los resultados políticos. Berrebi y Klor (2008) analizan el rol del terrorismo, en el caso del conflicto Israel-Palestina, y la manera en que el mismo incrementa las preferencias políticas de los israelitas hacia la derecha. Wood (2003) señala la existencia de procesos sociales que implican cambios en las identidades, intereses y roles de los actores que se ven afectados por los mismos.

En ese sentido, el panorama que ofrece el caso colombiano nos impone la necesidad de analizar las relaciones que se tejen en torno a ambos fenómenos. El mismo panorama subraya la importancia de reconocer la influencia de los contextos sociales y políticos en los que se llevan a cabo los procedimientos democráticos (García, 2007), incluso algunos autores han empezado a analizar las profundas conexiones existentes entre el conflicto armado y el funcionamiento de la democracia (López y Sevillano 2008; Nasi, 2007; Hoyos, 2008).

No obstante, persiste un vacío en tanto que no existen investigaciones que vinculen la violencia política con las carreras políticas, puesto que los estudios que hay en este campo de investigación, suelen concentrarse en los efectos político-electorales del conflicto armado en relación con variables como la participación política o la movilización electoral (García, 2010). Particularmente, centrados en el paramilitarismo, existen trabajos que revisan cuáles han sido los tipos de comportamiento en relación con los procesos electorales (Acemoglu, Robinson y Santos, 2009; Duncan, 2005; Gutiérrez Sanín, 2007; Hoyos, 2008; Losada, 2006). Sin embargo, no hay muchas investigaciones que vinculen las decisiones de los políticos en estos contextos violentos como tampoco con la manera en que se estructuran las carreras políticas.

Es más, cuando se ha estudiado la relación entre clase política y actores armados, encontramos el fenómeno de la parapolítica. Este fenómeno se ha estudiado desde la explicación y comprensión de los diferentes pactos regionales que originan toda una red de poder dirigida por los grupos paramilitares (López y Sevillano, 2008). 
Ahora bien, el equipo de investigación de la Corporación Nuevo Arcoíris agregó a la interpretación de la realidad colombiana, el concepto de captura y reconfiguración cooptada del Estado. Así, ha argumentado que los actores armados llevan a cabo "procesos de captura invertida del Estado" (López y Sevillano, 2008, p. 46) que les permite tener acceso a recursos económicos, informacionales y políticos que ponen en duda la legitimidad del Estado en los territorios.

\section{Fin del Conflicto... Pero con las FARC}

Si bien la historia del conflicto armado colombiano no tiene un solo protagonista, las FARC han marcado el devenir del conflicto y la violencia, al menos en los últimos sesenta años. Esta organización tuvo grandes mutaciones y cambios relevantes de sus actividades, ideologías y participación en acciones delictivas como el secuestro, la extorsión, el narcotráfico, el terrorismo, entre otras. ${ }^{4}$

El Estado colombiano estuvo durante más de seis décadas enfrentando a esta organización con los mecanismos y operadores de seguridad del momento. Importantes operativos militares y policiales junto a grandes capturas y neutralizaciones de gran impacto estratégico, sin duda, debilitaron militarmente a dicha agrupación; no obstante, a pesar de las victorias militares del Estado, el grupo al margen de la ley nunca desapareció. Era una evidente guerra de desgaste y lucha asimétrica.

De este modo, la paz en Colombia está indefectiblemente ligada al logro de un acuerdo entre el Estado y las FARC (Rangel, Arteta, Lozano, y Medina, 2008), pues no en vano por más de treinta años distintos gobiernos han intentado sentarse a negociar una salida al conflicto, pero todos sin éxito. Algunos de esos gobiernos pudieron avanzar en cuestiones sustanciales y

4 Una clara descripción de las Farc se encuentra en Pizarro (2010) Aguilera (2013; 2014) así como Centro Nacional de Memoria Histórica (2013). 
estructurales, otros lo usaban como bastión en campañas electorales, pero lo cierto es que la nación necesitaba urgentemente ponerle fin.

En Colombia, llevamos adelantado un acumulado de experiencias, buenas prácticas, y desarrollos institucionales y políticos en el elusivo camino de lograr la finalización del conflicto armado. Más que hablar de construcción de paz, ${ }^{5}$ el camino que lleva a los intentos de negociación política con los grupos armados ilegales puede ser caracterizado como la construcción e implementación de una política, sujeta a diferentes reformulaciones, de acuerdo con las coyunturas políticas en que se desarrolló. De hecho, como lo expresa Ana María Bejarano, "no debe sorprendernos el que en Colombia la historia de los procesos de paz haya corrido de forma paralela a las reformas políticas" (Bejarano, 2010, p. 47).

Un proceso de negociación de paz busca transformar una amenaza militar en un actor político, para ello se hace uso de la figura de acuerdos de paz que pueden ser definidos como un acuerdo explícito, pero no siempre explicitado o justificado públicamente, entre un grupo selecto de actores los cuales buscan definir o, mejor, redefinir reglas que gobiernan el ejercicio del poder bajo la base de mutuas garantías y la protección de los intereses vitales de aquellos que entran en él (O’Donnell, Schmitter y Whitehead, 1986).

En ese sentido, surgen algunas preguntas básicas que debe tener en cuenta una política de negociación y paz. La primera de ellas es ¿por qué negociar?

Una negociación de paz viene facilitada por dos grandes opciones: la imposibilidad de una victoria militar o el alto costo político de la misma. Así pues, los actores políticos en cada coyuntura enfrentan el cálculo de decidir si las condiciones están dadas, o no, para el inicio de una posible negociación. Cada proceso de negociación en Colombia, según lo documenta Eduardo Pizarro (2015), ha estado sopesado por la posibilidad de derrotar militarmente al enemigo como condición previa al inicio de acercamientos. Por

5 Para mayor información remitimos al lector al capítulo del libro de Rettberg (2012). 
ejemplo, durante el Gobierno de Andrés Pastrana (1998-2002) cada actor llegó a la mesa de diálogo con una expectativa diferente.

En el caso de las FARC, es posible afirmar que dicha decisión táctica fue producto de un diseño: las FARC seguían persiguiendo el poder político del Estado (y no una autonomía territorial o una incorporación limitada a la vida institucional), sentían que sus avances militares (particularmente en el periodo 1995-1998) favorecían su estrategia de expansión y carecían de un liderazgo unificado y pragmático que compartiera una visión común y consecuente del proceso de diálogo que estaba por iniciarse. En el caso del Ejecutivo, "la decisión fue táctica por default, Pastrana buscó una victoria electoral en la segunda vuelta con el tema de la paz y el contacto directo con las FARC" (Tokatlían, 2004, p. 639).

Ahora bien, toda negociación parte de dos presupuestos básicos: en primer lugar, el reconocimiento mutuo de los actores, esto es, que la organización en armas reconozca la legitimidad del Estado y que el Estado considere al contendor como un actor incurso en delitos políticos y, en ese reconocimiento, se logran posibilidades de acercamiento. Nótese, por ejemplo, que la denominación de amenaza terrorista por parte del Gobierno de Álvaro Uribe Vélez (2002-2006 y 2006-2010) implicó que "el Gobierno colombiano alineó su propia guerra contra los grupos insurgentes con la guerra contra el terrorismo global" (Borda, 2012, p. 99), así que no fue necesaria una negociación política para acabar con los grupos terroristas y proceder igualmente a su sometimiento a la justicia.

En segundo lugar, la convicción de las partes de la imposibilidad de la derrota militar del adversario y la mirada de la negociación como una buena oportunidad para reformar el sistema político.

El proceso de paz entre el Gobierno de Juan Manuel Santos y las FARC inició en 2012 luego de acercamientos previos entre las partes. La mesa de conversaciones de La Habana con las FARC se instaló después de una primera fase exploratoria en la más estricta reserva y confidencialidad con 
miembros delegados de dicho grupo armado (Oficina del Alto Comisionado para la Paz, 2016). El 26 de agosto de 2012, se firmó el documento que marcó el comienzo del proceso para dar fin al conflicto armado con las FARC (Revista Semana, 2015). La mesa estuvo guiada por seis puntos:

1. Política de Desarrollo agrario integral.

2. Participación política.

3. Fin del conflicto.

4. Solución al problema de las drogas ilícitas.

5. Víctimas.

6. Implementación, verificación y refrendación

(“Acuerdo Final para la Terminación del Conflicto y la Construcción de una paz estable y duradera", 2016).

Dentro del diseño de la negociación de La Habana, los puntos anteriores fueron trabajados por los equipos negociadores con acompañamiento internacional, ya sea en el rol de garantes (Cuba y Noruega) u observadores internacionales (Venezuela y Chile); pese a ello, hubo tensiones y puntos críticos durante los años de negociación.

\section{Los Retos de la Implementación de la Paz}

Tras la firma del Acuerdo de Paz en septiembre de 2016, el Gobierno del presidente Juan Manuel Santos consultó a la ciudadanía la aprobación de este. ${ }^{6}$ Aunque parecía que no estaba en los cálculos del grupo opositor al Acuerdo, la opción que ganó el 2 de octubre de ese año fue el no.

6 La pregunta literal del plebiscito se señalaba así: “¿Apoya usted el acuerdo final para la terminación del conflicto y la construcción de una paz estable y duradera?" 
De esta manera, en noviembre de 2016, comenzó un proceso de renegociación de los contenidos de la negociación que condujo a la firma de un nuevo acuerdo. Sin embargo, el desarrollo legislativo, político y programático del texto no ha sido tan eficiente como se esperaba entre quienes apoyaban el proceso. Por ejemplo, The Kroc Institute for International Peace Studies, señaló en su último informe que:

(...) el Acuerdo Final ha alcanzado un progreso significativo, especialmente, en compromisos que requieren logros a corto plazo como la dejación de las armas, el cese al fuego y de hostilidades, y el establecimiento de mecanismos de verificación y resolución de disputas, lo que lo ubica, en términos comparativos, en una posición igual o levemente superior frente a otros procesos de paz en el mundo. Estos avances establecen algunos pilares estructurales de la implementación del Acuerdo que deben cimentarse con las medidas de protección y seguridad en los territorios, el proceso de reincorporación de los excombatientes, y la Jurisdicción Especial para la Paz-JEP. (2017, pp. 17-19).

Por ello es importante tener en cuenta algunos elementos respecto de la implementación de los procesos de paz.

Por lo general, la implementación, se concentra en el ámbito nacional con temas tales como las misiones de paz o misiones políticas o la intervención de la comunidad internacional (Prendergast y Plumb, 2002). Pero, es importante concentrarse en el territorio local/regional para evidenciar la forma en que los acuerdos de paz generan impactos sobre las poblaciones y sobre la institucionalidad.

Estos procesos son entendidos como los esfuerzos a corto plazo relativos al cumplimiento de lo pactado por las partes en cuestión (Stedman, 2002). En la realidad, lo vemos en la coyuntura noticiosa, no son para nada sencillos, pues implica tener en cuenta el contexto sociopolítico, las restricciones políticas y la capacidad institucional con la que cuenta el Estado para llevar a cabo los cambios y compromisos que tengan lugar. 
Una variable que no se puede olvidar es que para que funcionen los acuerdos de paz se necesita el desarrollo de la pertenencia local local ownership (Chesterman, 2007) que permite estabilizar los arreglos institucionales y la gestión pública local necesarios para movilizar los acuerdos de paz (Rettberg y Quiroga, 2016).

Por lo tanto, el llamado que podría hacerse es promover una institucionalización de los acuerdos de paz (Hartzell y Hoddie, 2007) lo que se puede lograr por medio del fortalecimiento de la institucionalidad estatal producto de la negociación.

Aunque enfrenta muchos retos (problemas para tramitar los desarrollos legales de acuerdo con el Congreso, el riesgo que implican las disidencias y los ejercicios armados de copamiento territorial por parte de otros actores ilegales, el asesinato de líderes sociales), el período de implementación de los acuerdos de paz estará signado por el énfasis en el aspecto territorial. En este sentido, se podría esperar que la armonización entre la agenda nacional, departamental y municipal sea integral. Por lo menos, en la mente de quienes formulan la estrategia nacional de implementación de los acuerdos, no hay lugar a la existencia de intereses diferentes a una óptima (y urgente) sinergia territorial, pues, "en general toda Colombia hace parte del posconflicto. Hay algunos municipios donde los programas son más intensos que otros, pero no hay ningún municipio que esté excluido" (El País, 2016).

El conflicto armado culminó aquel día con las FARC como grupo armado ilegal, pero los retos y desafíos para la paz apenas comenzaron. Los problemas estructurales de la violencia y el conflicto armado siguen latentes. La tenencia de la tierra, el narcotráfico, la reparación a las víctimas y la garantía de no repetición, son los puntos de partida sobre los cuales inicia un nuevo capítulo en la historia contemporánea del país. 


\section{A Manera de Cierre}

En primer lugar, la sociedad colombiana y las instituciones del Estado tienen el gran reto que consiste en desfarcarizar la nación. Un proceso que puede ser incluso terapéutico para lograr finalmente la construcción de nación. Colombia llegó, en su momento, a ser el país más violento de Occidente, sin embargo, entre todas las naciones latinoamericanas, ninguna ha poseído un desarrollo sostenido como el colombiano en las últimas tres décadas (Zuleta, 2015). Lo importante, pese a las reacciones a favor y en contra del acuerdo logrado con las FARC, es terminar los demás conflictos y evitar la violencia como vaso comunicante en la sociedad.

En ese sentido, lo que queda por hacer es lo siguiente:

a. Reparar a las víctimas del conflicto.

b. Terminar de llevar al Estado a las zonas periféricas del país

c. Eliminar la "cultura del crimen" en algunos sectores de la población.

d. Fortalecer las instituciones estatales.

e. Administrar una justicia eficaz que reduzca los riesgos a la impunidad.

f. Atacar las disidencias y rezagos de los grupos armados ya neutralizados.

g. Atacar los demás grupos organizados que son actores del conflicto armado.

h. Satisfacer las necesidades básicas de la población.

i. Combatir de manera exitosa el narcotráfico y las nuevas formas de hacer el crimen, es decir, los mercados de la violencia. 
j. Transformación cultural y re-humanización del otro.

k. Desecuritizar la seguridad en el país

"Mucho más que las del monte, las violencias que nos están matando son las de la calle" (Posada, 2006).

\section{Referencias}

Acemoglu, D., Robinson, J. A., y Santos, R. (2013). The Monopoly of Violence. Journal of the European Economic Association, 11, 5-44. doi: 10.1017/CBO9781107415324.004

Aguilera, M. (2013). Contrapoder y justicia guerrillera. Fragmentación politica y orden insurgente en Colombia (1952-2003). Bogotá, Colombia: Debate.

Arjona, A. M. (2008). Grupos armados, comunidades y órdenes locales: interacciones complejas. En F. González (Ed.), Hacia la Reconstrucción del País. Bogotá, Colombia: CINEP-ODECOFI.

Arjona, A. M. (2015). Civilian Resistance to Rebel Governance. En N. Kasfir y Z. Mampilly (Eds.), Rebel Governance in Civil War (pp. 180-202). Cambridge, Massachusetts, United States: Cambridge University Press.

Arjona, A., Kasfir, N., y Mampilly, Z. (2015). Rebel Governance in Civil War. Cambridge, Massachusetts, United States: Cambridge University Press. doi: 10.1017/CBO9781316182468

Banco Mundial (2018). Estadísticas Colombia. Recuperado de https://datos. bancomundial.org/pais/colombia 
Berrebi, C., y Klor, E. (2008). Are Voters Sensitive to Terrorism? Direct Evidence from the Israeli Electorate. American Political Science Review, 102(3), 279-301. doi: 10.1017/S0003055408080246

Bejarano, A. (2010). Conflicto prolongado, múltiples protagonistas y negociaciones escalonadas. En A. Rettberg (Ed.), Conflicto armado, seguridad y construcción de paz en Colombia (pp. 43-69). Bogotá, Colombia: Uniandes - Ceso.

Borda, S. (2012). La internacionalización de la paz y de la guerra en Colombia durante los Gobierno de Andrés Pastrana y Álvaro Uribe. Búsqueda de legitimidad politica y capacidad militar. Bogotá, Colombia: Uniandes - Ceso.

Campos, G., Fals-Borda, O., y Umaña, E. (2005). La violencia en Colombia. Bogotá, Colombia: Taurus.

Castro, G. (1998). En secreto. Bogotá, Colombia: Editorial Planeta.

Camacho, A. (2006). De narcos, paracracias y mafias. En F. Leal Buitrago (Ed.), En la encrucijada. Colombia en el siglo XXI. Bogotá: Centro de Estudios Sociales (CESO), Grupo Editorial Norma.

Centro Nacional de Memoria Histórica (2013). Guerrilla y población civil. Trayectoria de las FARC 1949-2013. Bogotá, Colombia: Imprenta Nacional de Colombia.

Centro Nacional de Memoria Histórica (2013). ¡Basta ya! Colombia: memorias de guerra y dignidad. Bogotá, Colombia: Imprenta Nacional de Colombia.

Chesterman, S. (2007). Ownership in Theory and in Practice: Transfer of Authority in UN Statebuilding Operations. Journal of Intervention and Statebuilding, 1(1), 3-26. doi: 10.1080/17502970601075873 
Collier, P. (1998). On economic causes of civil war. Oxford Economic Papers, 50(4), 563-573. doi: 10.1093/oep/50.4.563

Comisión de Estudios sobre la Violencia (1987). Colombia, violencia y democracia: informe presentado al Ministerio de Gobierno. Bogotá, Colombia: Centro Editorial, Universidad Nacional de Colombia.

Comisión Histórica del Conflicto y sus Víctimas (2015). Contribución al entendimiento del conflicto armado en Colombia [Informe]. Recuperado de www.altocomisionadoparalapaz.gov.co

Crandall, R. (2002). Driven by Drugs: US Policy Toward Colombia. Boulder - London, United Kingdom: Lynne Rienner Publishers, Inc.

Deas, M., Malcolm, D., y Gaitán, F. (1995). Dos ensayos especulativos sobre la violencia en Colombia. Bogotá, Colombia: FONADE, Departamento Nacional de Planeación- Tercer Mundo Editores.

Departamento Nacional de Estadística. (2018). Demografía y población. Recuperado de https://www.dane.gov.co/index.php/estadisticas-por-tema/ demografia-y-poblacion

El País (2016). "Toda Colombia hace parte del posconflicto": Rafael Pardo. Recuperado de https:/www.elpais.com.co/elpais/colombia/proceso-paz/ noticias/toda-colombia-hace-parte-posconflicto-rafael-pardo

Fajardo, D. (2014). Estudio sobre los orígenes del conflicto social armado, razones de su persistencia y sus efectos más profundos en la sociedad colombiana. Bogotá, Colombia: Comisión Histórica del conflicto y sus víctimas.

Galtung, J. (1990). Cultural Violence. Journal of Peace Research, 27(3), 291-305. doi: 10.1177/0022343390027003005 
Galtung, J. (2003). Trascender y transformar. Una introducción al trabajo de conflictos. México D.F., México: Transcend - Quimera.

García, M. (2007). Sobre balas y votos: violencia política y participación electoral en Colombia 1990-1994. En D. Hoyos (Ed.), Entre la persistencia y el cambio. Reconfiguración del escenario partidista y electoral en Colombia (pp. 49-84). Bogotá, Colombia: Universidad El Rosario.

García, M. (2010). Bajo la mira de los actores armados. Contextos violentos, participación política e intención de voto en Colombia. En A. Rettberg (Ed.), Conflicto armado, seguridad y construcción de paz en Colombia (pp. 159-203). Bogotá, Colombia: Universidad de los Andes, Facultad de Ciencias Sociales, Departamento de Ciencia Política - CESO.

Garzón, J. (2 de diciembre de 2013). Las FARC y el narcotráfico: el motivo y el pretexto. Razón Pública. Recuperado de https://www.razonpublica. com/index.php/conflicto-drogas-y-paz-temas-30/7228-las-farc-y-elnarcotr\%C3\%A1fico-el-motivo-y-el-pretexto.html

Gehring, H., y Cuervo, M. (2013). Narcotráfico: el gran desafio para la superación del conflicto armado en Colombia. Bogotá, Colombia: Konrad Adenauer Stiftung.

Giraldo Ramírez, J. (2015). Las ideas en la guerra. Justificación y crítica en la Colombia contemporánea. Bogotá, Colombia: Debate.

Gómez-Albarello, J., y Rodríguez, J. (2007). Competencia electoral en grandes circunscripciones: el caso del Senado Colombiano. En D. Hoyos (Ed.), Entre la persistencia y el cambio. Reconformación del escenario partidista y electoral en Colombia (p. 216). Bogotá, Colombia: Editorial Universidad del Rosario.

González, F. (2014). Poder y violencia en Colombia. Bogotá, Colombia: Pontificia Universidad Javeriana - ODECOFI - CINEP. 
Grasa, R. (2017). La terminación del conflicto armado y la construcción de una paz estable y duradera en Colombia. Analecta Politica, 7(12), 7-17.

Guáqueta, A. (2002). Dimensiones políticas y económicas del conflicto armado en Colombia: anotaciones teóricas y empíricas. Colombia Internacional, (55), 20-36. doi: 10.7440/colombiaint55.2002.01

Gurr, T. R. (1970). Why men rebel. Princeton, NJ, United States: Princeton University Press.

Gutiérrez Sanín, F. (2014a). El Orangután con sacoleva. Cien años de democracia y represión en Colombia (1910-2010). Bogotá, Colombia: Debate.

Gutiérrez Sanín, F. (2014b). Propiedad, seguridad y despojo: el caso paramilitar. Estudios Socio-Jurídicos, 16(1), 43-74. doi: 10.12804/ esj16.1.2014.01

Gutiérrez-Sanín, F., y Wood, E.J. (2017). What Should We Mean by "Pattern of Political Violence"? Repertoire, Targeting, Frequency, and Technique. Perspectives on Politics, 15(1), 20-41. doi: 10.1017/S1537592716004114

Hartzell, C., y Hoddie, M. (2007). Crafting Peace: Power-Sharing Institutions and the Negotiated Settlement of Civil Wars. Pennsylvania, United States: The Pennsilvania State University Press.

Hobsbawm, E. (1974). Rebeldes primitivos. Barcelona, España: Ariel.

Hoyos, D. (2008). Dinámicas político-electorales en zonas de influencia paramilitar. Análisis de la competencia y la participación electoral. Revista Análisis Politico, (65), 13-32.

Hueso, V. (2000). Johan Galtung: la transformación de los conflictos por medios pacíficos. Cuadernos de estrategia, 111, 125-159. 
Kalyvas, S. N. (2006). The Logic of Violence in Civil War (1. ${ }^{a}$ Ed.). Cambridge, Massachusetts, United States: Cambridge University Press. doi: 10.1017/ CBO9780511818462

Kalyvas, S. N. (2009). Civil Wars. En C. Boix, y S. C. Stokes (Eds.), The Oxford Handbook of Comparative Politics (1. ${ }^{\mathrm{a}} \mathrm{Ed}$, pp. 415-434). Oxford: Oxford University Press. doi: 10.1093/oxfordhb/9780199566020.003.0018

LeGrand, C. (2016). Colonización y protesta campesina en Colombia, 18501950 (2. ${ }^{a}$ Ed.). Bogotá, Colombia: Ediciones Uniandes.

López, C., y Sevillano, O. (2008). Balance político de la parapolítica. Revista Arcanos, 14, 62-87

Medina Gallego, C. (2010). Farc-Ep y Eln una historia politica comparada (1958- 2006) [Tesis de doctorado]. Universidad Nacional de Colombia, Bogotá. Recuperado de http://www.bdigital.unal.edu.co/3556/

Meertens, D., y Sánchez, G. (1983). Bandoleros, gamonales y campesinos. El caso de la violencia en Colombia. (1. ${ }^{\mathrm{a}}$ Ed.). Bogotá, Colombia: E1 Áncora Editores.

Mujica, M., y Thoumi, F. (1996). Las negociaciones de pazy la participación de las guerrillas colombianas en el narcotráfico. Colombia Internacional, 36, 41-47. doi: 10.7440/colombiaint36.1996.07

Newman, E., y DeRouen, K. (2014). Routledge Handbook of Civil Wars (1. ${ }^{\mathrm{a}}$ Ed.). Routledge.

Niño, C. (2016). El narcotráfico mutante: nueva perspectiva de análisis del fenómeno en Colombia. Revista Cientifica General José Maria Córdova. Revista colombiana sobre investigación en el campo militar, 14(18), 113-124. doi: 10.21830/19006586.45 
Niño, C. (2017). Breve historia del conflicto armado en Colombia (reseña). Revista de Paz y Conflictos, 10(1), 327-330.

O’Donnell, G., Schmitter, P. C., y Whitehead, L. (Eds.) (1986). Transitions from Authoritarian Rule: Comparative Perspectives. Baltimore, United States: Johns Hopkins University Press.

Oficina del Alto Comisionado para la Paz. (12 de noviembre de 2016). Acuerdo Final para la Terminación del Conflicto y la Construcción de una paz estable y duradera. Oficina del Alto Comisionado para la Paz.

Ortiz, C. M. (1985). Estado y subversión en Colombia: La violencia en el Quindío, años 50. Bogotá, Colombia: CIDER - UNIANDES.

Oquist, P. (1978). Violencia, conflicto y politica en Colombia. Bogotá, Colombia: Biblioteca Popular.

Pécaut, D. (2008). Las FARC: fuentes de su longevidad y de la conservación de su cohesión. Revista Análisis Político, 21(63), 22-50. Recuperado de http://revistas.unal.edu.co/index.php/anpol/article/view/46015

Pécaut, D. (12 de marzo de 2014). Una lucha armada al servicio del statu quo social y politico. Recuperado de: http://www.altocomisionadoparalapaz.gov.co

Pizarro, E. (2002). Colombia: ¿guerra civil, guerra contra la sociedad, guerra antiterrorista o guerra ambigua? Análisis Político, (46), 164-181.

Pizarro, E. (2015). Una lectura múltiple y pluralista de la bistoria. Comisión de Historia del Conflicto y sus Victimas [Relatoría]. Bogotá D.C, Colombia.

Posada, E. (2006). La Nación Soñada. Bogotá, Colombia: Grupo Editorial Norma. 
Prendergast, J., y Plumb, E. (2002). Building Local Capacity: From implementation to peacebuilding. En S. Stedman, D. Rothchild, y E. Cousens (Eds.), Ending Civil Wars. The implementation of peace agreements (pp. 327-353). Boulder - London, United Kingdom: Lynne Rienner Publishers.

Proceso de paz: Así comenzó todo (8 de agosto de 2015). Revista Semana. Recuperado de http://www.semana.com/nacion/articulo/ proceso-de-paz-asi-comenzo-todo/440079-3

Rangel, A., Arteta, Y., Lozano, C., y Medina, M. (2008). Qué, cómo, y cuándo negociar con las FARC. Bogotá, Colombia: Intermedio.

Rettberg, A. (2012). Construcción de paz en Colombia: contexto y balance. En Autor (Ed.), Construcción de paz en Colombia (pp. 3-50). Bogotá, Colombia: Uniandes - Ceso. doi: 10.7440/2012.23

Rettberg, A., y Quiroga, D. (2016). Más allá de La firma: Las elecciones legislativas (2014) y locales (2015) y El futuro de implementación de la Paz en Colombia (Beyond the Signature: Local and Congressional Elections and the Future of Peace Implementation in Colombia). doi: 10.2139/ ssrn. 2718732

Ríos, J. (2017). Breve historia del conflicto armado en Colombia. Madrid, España: La Catarata.

Rodríguez, E. (2016). Discurso, representaciones y significados del conflicto armado en Colombia: un análisis prospectivo. En C. Niño (Ed.), Perspectivas y prospectivas de la seguridad en Colombia (pp. 15-33). Bogotá, Colombia: Ediciones USTA. doi: 10.2307/j.ctvb9391v.5

Ronderos, M. T. (2014). Guerras recicladas. Bogotá, Colombia: Penguin Random House Grupo Editorial Colombia. 
Romero, M. (2002). Democratización política y contrarreforma paramilitar en Colombia. Politica y Sociedad, 39(1), 273-292.

Romero, M. (2003). Paramilitares y autodefensas. Bogotá, Colombia: Planeta, IEPRI, Universidad Nacional de Colombia.

Sánchez, F., y Chacón, M. (2007). Conflicto, Estado y descentralización del progreso social a la disputa armada por el control local, 1974-2008. En: F. Gutiérrez, M. Wills, y G. Sánchez (Eds.), Nuestra Guerra sin Nombre, Transformaciones del Conflicto en Colombia. Bogotá, Colombia: Instituto de Estudios Políticos y Relaciones Internacionales (IEPRI), Universidad Nacional de Colombia, Grupo Editorial Norma

Stedman, S. (2002). Introduction. En S. Stedman, D. Rothchild, y E. Cousens (Eds.), Ending Civil Wars. The implementation of peace agreements (pp. 1-3). Boulder - London, United Kingdom: Lynne Rienner Publishers.

The Kroc Institute for International Peace Studies (2017). Informe sobre el estado efectivo de implementación del acuerdo de paz en Colombia (p. 119). Notre Dame, France: Universidad de Notre Dame. Recuperado de https://kroc.nd.edu/assets/257593/informe_kroc.pdf

Tokatlian, J. (2004). Una reflexión en torno a Colombia, 1999-2002: ¿negociación para la paz o proceso para la guerra? Foro Internacional, $178,635-655$

Tulchin, J., y Espach, R. (2001). Latin America in the New International System. Boulder: Lynne Rienner.

Uprimny, R., Guzmán, D., y Parra, J. (28 de noviembre de 2012). Diálogos de paz y drogas: posibilidades en medio y más allá del prohibicionismo. De Justicia. Recuperado de https://www.dejusticia.org/wp-content/ uploads/2017/04/fi_name_recurso_328.pdf 
Weber, M. (1964). Economía y sociedad. Esbozo de sociología comprensiva. (Trad. J. Medina) (1. ${ }^{\mathrm{a}}$ Ed.). México, D.F., México: Fondo De Cultura Económica.

Wimmer, A. (2013). Waves of War: Nationalism, State Formation, and Ethnic Exclusion in the Modern World. New York, United States: Cambridge University Press. doi: 10.1017/CBO9781139198318

Wood, E. J. (2003). Insurgent Collective Action and Civil War in El Salvador. Cambridge, Massachusetts, United States: Cambridge University Press. doi: 10.1017/CBO9780511808685

Yaffe, L. (2011). Conflicto armado en Colombia: análisis de las causas económicas, sociales e institucionales de la oposición violenta. Revista en Ciencias Sociales, (8), 187-208. doi. 10.18046/recs.i8.1133

Zuleta, E. (2015). Colombia: violencia, democracia y derechos humanos. Bogotá, Colombia: Ariel. 
